This item was submitted to Loughborough's Research Repository by the author.

Items in Figshare are protected by copyright, with all rights reserved, unless otherwise indicated.

\title{
When superhydrophobic coatings are icephobic: Role of surface topology
}

PLEASE CITE THE PUBLISHED VERSION

https://doi.org/10.1016/j.surfcoat.2018.11.039

\section{PUBLISHER}

(c) Elsevier

\section{VERSION}

AM (Accepted Manuscript)

\section{PUBLISHER STATEMENT}

This paper was accepted for publication in the journal Surface and Coatings Technology and the definitive published version is available at https://doi.org/10.1016/j.surfcoat.2018.11.039.

\section{LICENCE}

CC BY-NC-ND 4.0

\section{REPOSITORY RECORD}

Wu, Xinghua, Vadim Silberschmidt, Zhong-Ting Hu, and Zhong Chen. 2019. "When Superhydrophobic Coatings Are Icephobic: Role of Surface Topology". figshare. https://hdl.handle.net/2134/36398. 


\title{
When superhydrophobic coatings are icephobic: Role of surface topology
}

\author{
Xinghua $\mathrm{Wu}^{\mathrm{a}}$, Vadim V. Silberschmidt ${ }^{\mathrm{b}}$, Zhong-Ting $\mathrm{Hu}^{\mathrm{c}, *}$, Zhong Chen ${ }^{\mathrm{a}, *}$ \\ ${ }^{a}$ School of Materials Science and Engineering, Nanyang Technological University, 50 Nanyang Avenue, 639798, Singapore \\ ${ }^{\mathrm{b}}$ Wolfson School of Mechanical, Electrical and Manufacturing Engineering, Loughborough University, Loughborough, Leicestershire LE11 3TU, United Kingdom \\ ${ }^{\mathrm{c}}$ College of Environment, Zhejiang University of Technology, Hangzhou 310014, Zhejiang, PR China
}

\begin{abstract}
A B S T R A C T
Among different types of anti-icing coatings, superhydrophobic coatings have attracted considerable attention due to their water repellency and low heat-transfer rate. However, condensation on superhydrophobic surfaces at low temperatures usually causes an increase in ice adhesion because of the induced wetting of micro- and nanostructures. By tuning the weight ratio of surface-modified nanoparticles to unmodified ones, five superhydrophobic coatings with different structural features at the microscale were developed. Ice-adhesion strength and ice-nucleation temperature were studied, together with the effect of moisture condensation on ice adhesion. It was found that the ice-adhesion strength and icing temperature of these coatings do not necessarily follow the same order among these surfaces because of different mechanisms involved. Surface roughness is inadequate to describe the necessary surface features that critically affect the anti-icing behavior of the coatings. Detailed topology/geometry has to be considered when designing icephobic coatings. Superhydrophobic coatings can be adopted for icephobic applications once the surface topology is carefully designed.
\end{abstract}

\author{
Keywords: \\ Icephobic \\ Anti-icing \\ Superhydrophobic \\ Ice nucleation \\ Ice adhesion \\ Sol-gel
}

\section{Introduction}

Ice accretion in cold environment is natural and inevitable. Various studies were carried out focused on delaying ice formation and easy removal of formed ice. Over the past decades, superhydrophobic coatings have shown good promise to repel and shed water [1-4]. Researchers working in various fields mimicked natural superhydrophobic surfaces (plants, inspects, bacteria, skin of aquatic animals etc.) and designed numerous synthetic superhydrophobic surfaces. Metals [5-7], copolymers $[8,9]$, nanoparticles $[10,11]$, nanotubes [12,13], nanorods [14] and nanofibers [15,16] were employed to create air-trapping micro- and nanostructures. The involved methods include atom-transfer radical polymerization, electrodeposition, sol-gel, etching, lithography etc. The first study on anti-icing performance of superhydrophobic coatings was reported by Saito et al. in 1997 [17]. Later, various aspects of anti-icing behavior of superhydrophobic coatings was investigated, including ice inhibition, ice adhesion, ice accumulation and frost formation. Cao et al. [18] observed inhibition of ice formation on superhydrophobic coatings when supercooled water was poured onto a tilted surfaces. Momen et al. [19] found that superhydrophobic coatings greatly retarded water freezing. Jafari [20] and his co-workers showed that the superhydrophobic coating surface presented 3.5 times lower ice-adhesion strength than that of an uncoated surface. Zhao et al. [21] proved that superhydrophobic coatings could significantly restrain ice accumulation on insulator strings. He et al. [22] reported the retardation of frost formation on the superhydrophobic isotactic polypropylene film. Mishchenko et al. [23] designed a highly ordered superhydrophobic coating which can maintain ice-free down to ca. -25 to $-30^{\circ} \mathrm{C}$. Unfortunately, high water mobility and its low adhesion may not always be maintained because of its water condensation in texture [24-26] or drop impact beyond a texture-specific velocity [27]. Boinovich et al. [7] pointed out that the phase transition from supercooled water to ice induced a growth of a frost halo and a metastable iced meniscus near a three-phase contact line, which was responsible for the increased adhesive contact area between the droplet and the substrate.

Because of the outstanding water repellency and reduced heat transfer due to air trapping, robust anti-icing coatings maintaining superhydrophobicity when the temperature approached the dew-point $[28,29]$ or below zero degree $[30,31]$, still attract the interest of many researchers. With fine control of surface microstructures, favorable anti-icing performance can be achieved. For example, Fu et al. [2] designed a robust icephobic coating based on superhydrophobicity via optimizing the coating's surface structure with the help of nanoparticles. Similarly, colloidal surfaces with different content of fluorine

\footnotetext{
Abbreviations: DI, deionized; GLYMO, 3-glycidoxypropyltrimethoxysilane; PFOTES, 1H, 1H, 2H, 2H-perfluorooctyltriethoxysilane; PTFE, polytetrafluoroethylene; $\mathrm{RH}$, relative humidity; TEOS, tetraethyl orthosilicate

* Corresponding authors.

E-mail addresses: wuxi0011@e.ntu.edu.sg (X.Wu), zthu@zjut.edu.cn (Z.-T. Hu), ASZChen@ntu.edu.sg (Z. Chen).
} 
polymers were also developed [32]. The optimum coating demonstrated superhydrophobicity under freeze temperatures. Wang et al. [33] reported a flexible superhydrophobic coating which could repel water and ice even at $-20^{\circ} \mathrm{C}$ with a relative humidity (RH) of $90 \%$ for more than three months. Shen et al. [34] studied anti-icing properties of single nanostructured and micro-nanostructured superhydrophobic surfaces. They found that the single nanostructure surface demonstrated a reduced icing area and an icing mass than those of the micronanostructured surfaces. Emelyanenko et al. [35] verified a durable superhydrophobic coating with snow and ice accumulation in severe outdoor experiments for several months. Among all the studies, free energy and roughness of surfaces were found to be the main factors for anti-icing coatings. Extensive experiments were conducted to investigate the influence of these two factors on anti-icing performance. It is clear that lower surface energy of a surface results in lower ice adhesion [36-39] and lower icing probability [40,41]. However, roughness as a key characteristic of a surface could not reflect all the surface properties, especially for rough porous surfaces. Even a relatively small difference on a surface would result in a distinct ice-nucleation process. Therefore, attention is needed to study the effect of surface topology/ geometry on anti-icing performance of superhydrophobic coatings. In this study, five superhydrophobic coatings were created by tuning a weight ratio of surface modified and unmodified $\mathrm{SiO}_{2}$ nanoparticles in a sol-gel system. By adjusting the surface structure of the coatings, lower ice adhesion and suppressed ice nucleation can be achieved. The series of experiments have allowed identification the key factors behind various indicators of icephobic performance.

\section{Material and methods}

\subsection{Materials}

Tetraethyl orthosilicate (TEOS), 3-glycidoxypropyltrimethoxysilane (GLYMO), 1H, 1H, 2H, 2H-perfluorooctyltriethoxysilane (PFOTES), $\mathrm{SiO}_{2}$ nanoparticles with particle size around $10-20 \mathrm{~nm}$, and itaconic acid were obtained from Sigma-Aldrich. Methanol (99\%) was obtained from Fisher Scientific. Glycerol and formamide, used for surface-energy measurement, were obtained from Sigma-Aldrich. Microscope glass slides $(25.4 \mathrm{~mm} \times 76.2 \mathrm{~mm}$ ) and cover glass (diameter: $22 \mathrm{~mm}$ and thickness $0.13-0.16 \mathrm{~mm}$ ), used for ice-nucleation temperature tests, were obtained from Sailboat Lab Co. Ltd. and Marienfeld, respectively.

\subsection{Preparation method}

\subsubsection{Preparation of PFOTES-SiO ${ }_{2}$ nanoparticles}

The hydrolysis of PFOTES was implemented by mixing PFOTES, methanol and deionized (DI) water with a volume ratio of 1:96:3 for $24 \mathrm{~h}$. To prepare PFOTES-modified $\mathrm{SiO}_{2}$ nanoparticles, $0.25 \mathrm{~g} \mathrm{SiO}_{2}$ nanoparticles, $8 \mathrm{ml}$ methanol and $4 \mathrm{ml}$ hydrolyzed PFOTES were mixed at room temperature. Then the mixture was first placed in an ultrasonic bath for $30 \mathrm{~min}$, and then magnetically stirred for $24 \mathrm{~h}$. After stirring, the mixture was centrifuged at $2000 \mathrm{rpm}$ for $5 \mathrm{~min}$ (the obtained hydrophobic silica is subsequently denoted as PFOTES-SiO${ }_{2}$ ). In this step, a total amount of $4.25 \mathrm{~g} \mathrm{SiO}_{2}$ nanoparticles were modified to obtain PFOTES-SiO ${ }_{2}$ nanoparticles, which were used as fillers with low surface energy. The as-received $\mathrm{SiO}_{2}$ nanoparticles obtained from SigmaAldrich were used as fillers with high surface energy.

\subsubsection{Preparation of sol-gel}

TEOS-GLYMO sol was prepared by mixing $20 \mathrm{ml}$ methanol with $5 \mathrm{ml}$ 1 hydrolyzed PFOTES solution, $0.004 \mathrm{~mol}$ TEOS, $0.02 \mathrm{~mol}$ GLYMO, $0.076 \mathrm{~mol}$ DI water and $0.5 \mathrm{~g}$ itaconic acid for $4 \mathrm{~h}$ under magnetic stirring. Itaconic acid was used to acidify the sol to $\mathrm{pH} 3-4$. The PFOTES-SiO ${ }_{2}$ nanoparticles prepared in the first step were added to the TEOS-GLYMO sol. Then, $\mathrm{SiO}_{2}$ nanoparticles with high surface energy were added to keep the weight of total $\mathrm{SiO}_{2}$ nanoparticles at $1.5 \mathrm{~g}$ for 
each sample. The detailed weight of $\mathrm{SiO}_{2}$ nanoparticles with high and low surface energy in each sample is shown in Table 1. After that, the prepared sols were ultrasonically treated for $15 \mathrm{~min}$, and then stirred magnetically for $24 \mathrm{~h}$ before they were spray-coated onto the glass slides with an airbrush kit (AS06KB) with a $1.5 \mathrm{~mm}$ diameter nozzle using compressed air (pressure at $345 \mathrm{kPa}$ ). A distance between the airbrush and the substrate was kept at $10 \mathrm{~cm}$. The coating thickness was fixed at $30 \mu \mathrm{m}( \pm 10 \%)$. Finally, the prepared samples were cured in an oven at $110^{\circ} \mathrm{C}$ for $1.5 \mathrm{~h}$ and labelled as TGS $1: 5$, TGS 2:4, TGS 3:3, TGS 5:1 and TGS 6:0 corresponding to the weight ratio of PFOTES modified and unmodified $\mathrm{SiO}_{2}$ nanoparticles

\subsection{Characterization of coatings}

Surface morphology of the obtained coatings was scanned using a field emission scanning electron microscope (FESEM) (JSM-6360, Japan). Water wettability of coatings was measured with a contact angle system (OCA 20, Dataphysics Co., Germany). The corresponding values were obtained as an average of more than five measurements at different locations of the coatings. The surface energy was calculated based on contact angles of glycerol, formamide and water based on the OWRK method [42-44]. Surface roughness was measured with an atomic force microscope (AFM) with a scanning area of $10 \mu \mathrm{m} \times 10 \mu \mathrm{m}$. The roughness value was an average of at least three measurements obtained at different locations of the coatings.

For an ice-adhesion test, a polytetrafluoroethylene (PTFE) tube with an inner diameter of $18 \mathrm{~mm}$ was filled with DI water, and then covered with the sample on the top. The whole set was flipped upside down and placed inside a climate chamber (Cincinnati Sub-Zero environmental chambers, U.S.A.) for $24 \mathrm{~h}$ at $-15^{\circ} \mathrm{C}$ and $-20^{\circ} \mathrm{C}$. The weight of infilled water was $1.5 \mathrm{~g}$. Measurements of the ice-adhesion strength followed a previous report $[2,39]$. The reported ice-adhesion strength was an average value of at least six measurements on the same position of each sample, and a total of at least three samples of the same condition. To evaluate the effect of water condensation on the ice-adhesion strength, the coatings were kept in the climate chamber at $-20^{\circ} \mathrm{C}$ with $\mathrm{RH}$ of $80 \%$ for $24 \mathrm{~h}$ before they were taken out to perform the ice-adhesion test following the procedure described above. The obtained results revealed the resistance of the coatings to water condensation.

The ice-nucleation temperature of coatings was studied using our previously reported self-designed automatic measurement system [45]. A $10 \mu \mathrm{l}$ droplet of DI water was placed on the center of the coating on a thin cover-glass slide. The test chamber was cooled from $\sim 22^{\circ} \mathrm{C}$ to freezing temperature (target temperature set at $-30{ }^{\circ} \mathrm{C}$ ). The ramp rate from room temperature to $0{ }^{\circ} \mathrm{C}$ was set at $40^{\circ} \mathrm{C} / \mathrm{min}$, followed by $5{ }^{\circ} \mathrm{C}$ / min from $0{ }^{\circ} \mathrm{C}$ to the set $-30^{\circ} \mathrm{C}$ to minimize a heat reflux effect. The icing temperature of the coatings was defined as the temperature, at which a detected intensity of a reflected laser beam increased dramatically due to the ice formation. 500 icing-melting cycles were carried out for each water droplet. The results were recorded and statistically analyzed. To make sure that the iced droplet was heated up to ambient temperature and in an equilibrium state, the sample was held for $2 \mathrm{~min}$ after it has reached $22^{\circ} \mathrm{C}$ before the next cycle began.

\section{Results and discussion}

\subsection{Surface characteristics of coatings}

In order to fabricate coatings with different surface microstructures, the low-surface-energy PFOTES-SiO ${ }_{2}$ and high-surface-energy $\mathrm{SiO}_{2}$ nanoparticles with weight ratios of 1:5, 2:4, 3:3, 5:1 and 6:0 were added into the TEOS-GLYMO sol, while keeping the total weight percent of nanoparticles and other components the same. Fig. 1 shows FESEM images of these coatings. A significantly distinct surface topology of the TGS 1:5 coating compared to other coatings was observed. Large agglomerated clusters of several micrometers in size (Fig. 1a) can be seen on this surface. Increasing the weight ratio of PFOTES-SiO ${ }_{2}$ to $\mathrm{SiO}_{2}$ nanoparticles to 3:3 led to a decrease in the size of agglomerated $\mathrm{SiO}_{2}$ nanoparticles and an increase in porosity (Fig. 1a-c). The pore size is in the order of $1 \mu \mathrm{m}$ or less for sample TGS 3:3. Generally, both modified and unmodified nanoparticles are prone to agglomerate as illustrated in Fig. 2. When a portion of the PFOTES-SiO ${ }_{2}$ nanoparticles replaces the same portion of $\mathrm{SiO}_{2}$ nanoparticles, the modified $\mathrm{SiO}_{2}$ nanoparticles tend to attach to nanoparticles with high surface energy. In such a case, the PFOTES-SiO ${ }_{2}$ nanoparticles can serve as spacers to the unmodified $\mathrm{SiO}_{2}$ nanoparticles and hinder their agglomeration, resulting in an increased porosity in the coatings (Fig. 2). Continuously increasing the weight ratio of PFOTES-SiO ${ }_{2}$ to $\mathrm{SiO}_{2}$ nanoparticles from 3:3 to $6: 0$ caused a progressively increased size of agglomerated PFOTES-SiO nanoparticles (Fig. 2). The TGS 5:1 and TGS 6:0 coatings displayed larger agglomerated clusters than the TGS 3:3 coating (Fig. 1c-e). Although all these coatings (TGS1:5, TGS 2:4, TGS 3:3, TGS 5:1 and TGS 6:0) presented micro-nanostructures, smaller agglomerated clusters and more uniform distributions of micro-pores were noticed on the surface of TGS 3:3 coating because of the interaction of the low-surface-energy PFOTES-SiO ${ }_{2}$ and high-surface-energy $\mathrm{SiO}_{2}$ nanoparticles (Fig. 1c).

Water-contact angles and roll-off angles of the coatings are shown in Fig. 3a. All the coatings demonstrated water-contact angles larger than $150^{\circ}$ and roll-off angles smaller than $10^{\circ}$, indicating superhydrophobicity of all these coatings. It is well-known that water wettability is dominated by surface energy and surface roughness. Intrinsic surface energy of a rough surface is complex and difficult to measure. Herein, the apparent surface energy was measured instead, together with surface roughness (root-mean square, RMS). Although all the five coatings exhibited water repellency, the apparent surface energy decreased with the increasing PFOTES-SiO ${ }_{2}$ content (Fig. 3b). The measured surface roughness (Fig. $3 \mathrm{~b}$ ) is consistent with the FESEM images as shown in Fig. 1. The TGS 3:3 coating showed the lowest surface roughness at $\sim 390 \mathrm{~nm}$, while the other four coatings exhibited comparable levels of surface roughness at around $500 \mathrm{~nm}$. In summary, the five superhydrophobic coatings with different surface microstructures were obtained to enable further comparison and analysis the anti-icing performance.

\subsection{Ice-adhesion strength}

Ice-adhesion strength of the obtained coatings at temperature $-15^{\circ} \mathrm{C}$ and $-20^{\circ} \mathrm{C}$ is presented in Fig. 3c. Even though all five coatings demonstrated superhydrophobicity as defined by the contact angle and roll-off angle, they displayed very different ice-adhesion strength. A much higher ice-adhesion strength, in the range of $400-500 \mathrm{kPa}$, of the TGS $1: 5$ coating than the other coatings was observed. The TGS $3: 3$ and TGS 5:1 coatings presented comparable ice-adhesion strengths of $\sim 150 \mathrm{kPa}$ at $-15^{\circ} \mathrm{C}$ and $\sim 250 \mathrm{kPa}$ at $-20^{\circ} \mathrm{C}$, which are much lower than those of the TGS 1:5 coating. Only TGS 2:4 and TGS 6:0 coatings exhibited an ice-adhesion strength below $100 \mathrm{kPa}$, a key performance indicator for icephobic coatings $[46,47]$. The difference in the ice-adhesion strengths of the TGS $6: 0$ coating at $-15{ }^{\circ} \mathrm{C}$ and $-20{ }^{\circ} \mathrm{C}$ was the lowest among the five coatings. Between TGS 6:0 and TGS 3:3, the lower ice-adhesion strength of the TGS $6: 0$ coating might be due to its lower apparent surface energy. It should be recalled that the question whether a superhydrophobic coating is icephobic has been a topic of heated debates for several years and, till now, controversy remains. Some researchers showed low ice-adhesion strength of superhydrophobic surfaces, while others reported very high ice-adhesion strength of such coatings. Here, both cases were observed. The five designed coatings with different surface microstructures showed distinct ice-removal properties, and no simple correlation exists between the apparent surface energy and ice adhesion. There is also no simple correlation between the surface roughness, as indicated by the RMS (Fig. 3b), and the ice-adhesion strength. When the freezing of a water droplet on a hydrophobic or superhydrophobic surface is not 

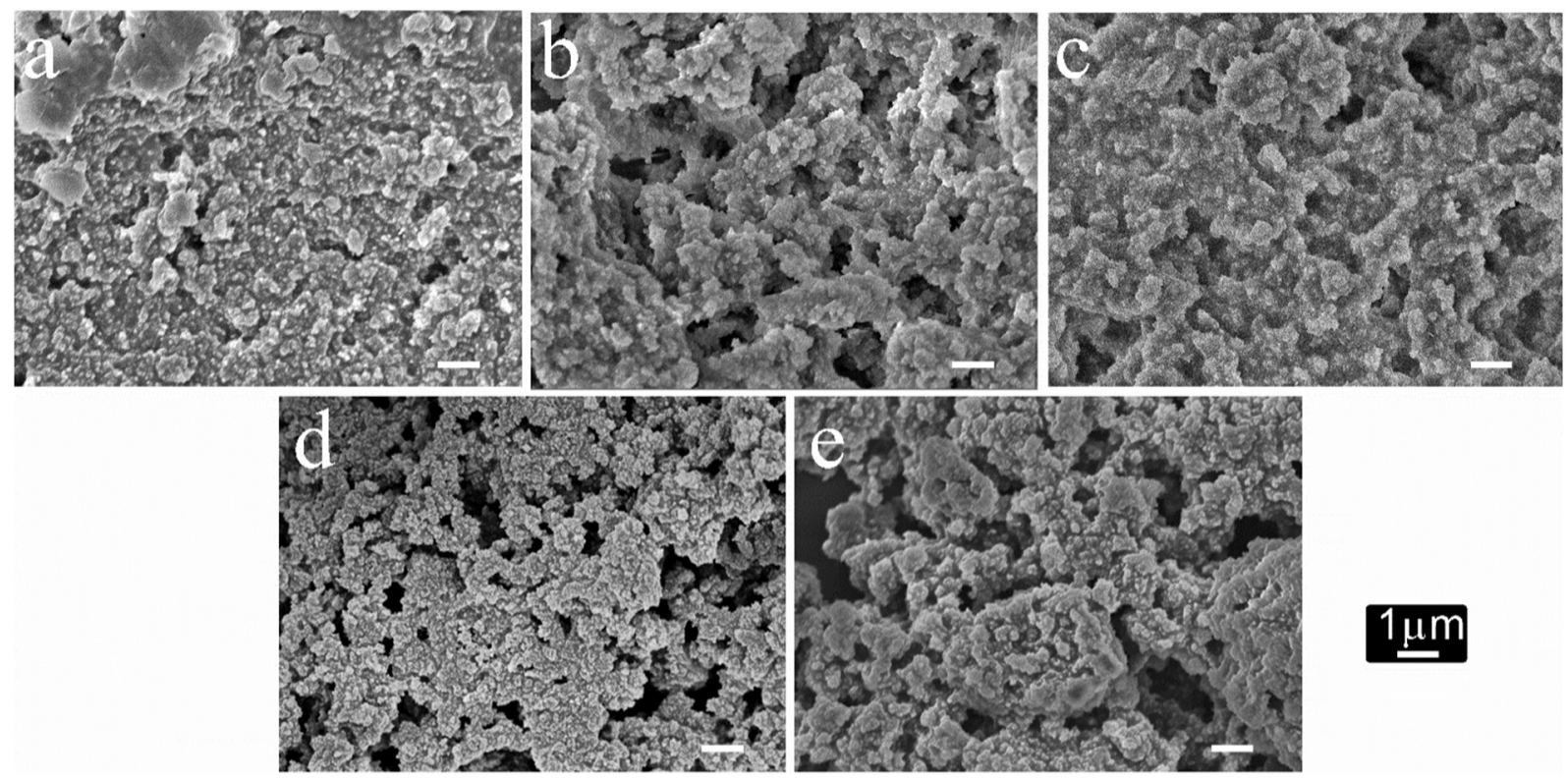

$1 \mu \mathrm{m}$

Fig. 1. Surface morphology of (a) TGS 1:5, (b) TGS 2:4, (c) TGS 3:3, (d) TGS 5:1 and (e) TGS 6:0 coatings with increased weight of PFOTES-SiO ${ }_{2}$ nanoparticles (the scale bar for all images is $1 \mu \mathrm{m}$ ).

\section{$\mathrm{SiO}_{2}$ nanoparticles}
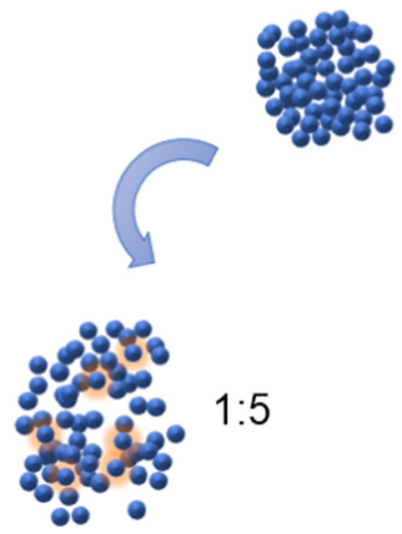

$1: 5$

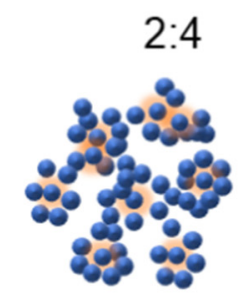

PFOTES - $\mathrm{SiO}_{2}$ nanoparticles
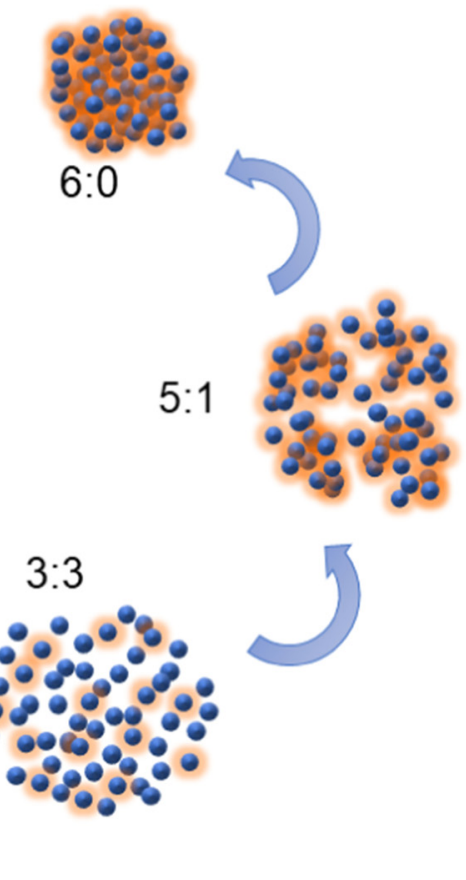

Fig. 2. Schematic illustration of interactions between $\mathrm{PFOTES}-\mathrm{SiO}_{2}$ and $\mathrm{SiO}_{2}$ nanoparticles.

accompanied with a transition from the Cassie-Baxter mode to the Wenzel mode, ice forms on the solid coating surface, while the trapped air remains in the surface cavities. In this case, the ice-adhesion strength will be greatly reduced. In the current study, the TGS 2:4 and TGS 6:0 coatings presented the Cassie-Baxter mode owing to the proper surface topology, which has resulted in a low ice adhesion. On the other hand, the highest ice adhesion of the TGS $1: 5$ coating is attributed to the transition from the Cassie-Baxter mode to the Wenzel mode. Water penetrated into the porous micro-structure of the TGS 1:5 coating during the sample preparation, resulting in the increased ice adhesion thorough mechanical interlocking. The moderate level of ice adhesion of the TGS 3:3 and TGS 5:1 coatings was probably caused by a partial wetting under the mixed Cassie and Wenzel mode.

Since the water-condensation effect poses a great threat to superhydrophobic coatings, a condensation test was carried out on the five coatings. The measured ice-adhesion strengths are shown in Fig. 3d. It is not surprising that TGS 1:5 exhibited nearly no increase in ice adhesion due to the Wenzel mode interaction between water and the coating surface. In contrast, ice adhesion of the TGS 2:4, TGS 3:3 and TGS 5:1 coatings increased significantly due to the condensation-induced transition from the Cassie mode to the mixed Cassie and Wenzel mode. The TGS 6:0 coating demonstrated robust icephobicity with only a slight increase in ice adhesion after the water condensation. Accordingly, it was possible to identify a robust icephobic coating, 

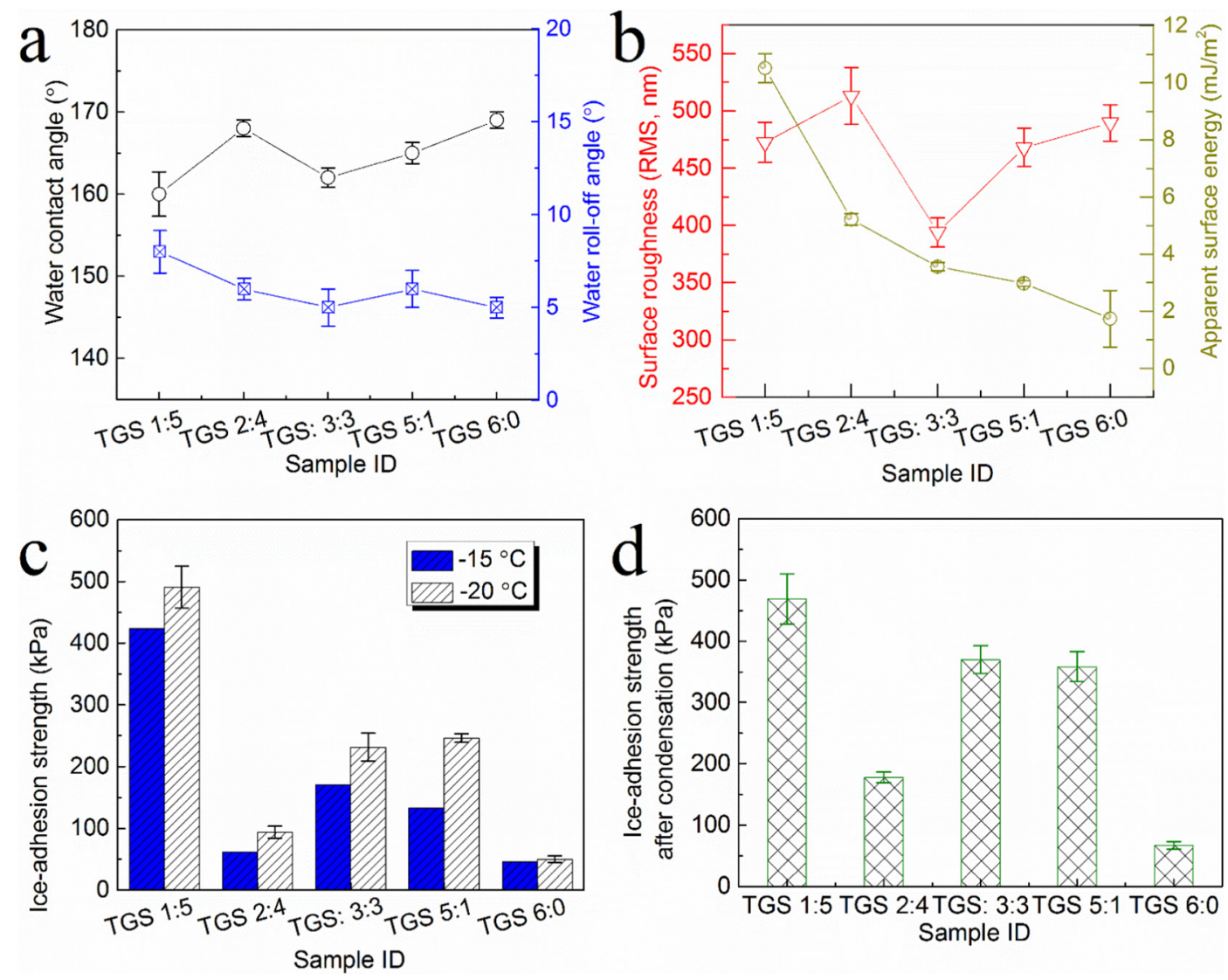

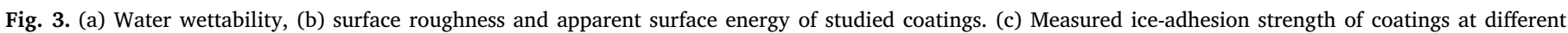
temperatures, and (d) ice-adhesion strength of coatings after water condensation for $24 \mathrm{~h}$ at $-20{ }^{\circ} \mathrm{C}$ with $\mathrm{RH}$ of $80 \%$.

resistant to moisture condensation before ice formation. Besides surface roughness and apparent surface energy, surface geometry of the sample plays an important role in the ice-removal performance. A lesson learnt from this study is that to design a robust icephobic coating, attention should be paid to the shape and size of micro-pores, along with the low surface energy requirement. Considering only a surface roughness value can be misleading, particularly when moisture condensation occurs before icing.

\subsection{Ice-nucleation behavior of superhydrophobic coatings}

In cold-climate regions, ice accretion on outdoor structures is natural and inevitable. However, anti-icing coatings are able to decrease the icing temperature and icing probability of a surface. Thus, icing can be delayed, or even prevented, when the temperature of a surface is higher than the icing temperature. To investigate the icing temperatures of the five coatings, 500 icing and deicing cycles from $-30{ }^{\circ} \mathrm{C}$ to $22^{\circ} \mathrm{C}$ were tested for each sample; the obtained results are shown in Fig. 4. The distribution of their icing events in the temperature range between $-20^{\circ} \mathrm{C}$ and $-30^{\circ} \mathrm{C}$ was analyzed statistically and fitted by the Gauss normalized curve (Fig. 5) following our previous studies [45]. The whole icing temperature range of $-20^{\circ} \mathrm{C}$ to $-30^{\circ} \mathrm{C}$ was binned with a bin width of $0.2^{\circ} \mathrm{C}$. The temperature of each curve's peak was chosen as the average ice-nucleation temperature of that coating (Table 2).

Furthermore, the number of freezing events was used to analyze the freezing probability $P$, defined as

$P=\frac{N_{i}}{N_{0}}$,

where $N_{i}$ is the freezing event in the $i_{t h}$ bin and $N_{0}$ the total number of icing events (500 in this study). To establish a relationship between the temperature and $P$, the temperature-survival curve $F(t)$ was defined as [48]

$F(t)=\frac{N(t)}{N_{0}}$,

where $N(t)$ is the number of unfrozen events at temperature $t$. The obtained results are shown in Fig. 6. At a certain temperature, the icing probability of the coatings (a portion of frozen events, the opposite to the portion of unfrozen events) from the lowest to the highest was TGS 3:3 < TGS 6:0 < TGS 5:1 < TGS 2:4 < TGS 1:5. The lowest icing probability of the TGS 3:3 coating might be due to its low surface energy coupled with suitable surface topology. Some researchers defined the temperature $t_{0.5}$, at which $F(t)=0.5$ as the average ice-nucleation temperature [49-52]. Herein, these results are also shown in Table 2 as a comparison of the Gauss-peak values for the coatings; a perfect agreement between the two is noticed. The ice-nucleation temperature of the coatings from the lowest to the highest was TGS $3: 3<$ TGS 6:0 < TGS 5:1 < TGS 2:4 < TGS 1:5. The TGS 3:3 coating presented the lowest ice-nucleation temperature of around $-27^{\circ} \mathrm{C}$. It is worth mentioning that the temperature-survival curves were based on 500 cycles, which is 2.5 times more than the threshold of 200 cycles necessary to obtain a stable curve [53]. The 10-90 widths (the range between 10th and 90th percentage of the frozen temperature) for the five coatings as shown in Table 2 are comparable to the data demonstrated in a previous report [54]. Therefore, the analysis of the temperature-survival curves can be considered reliable.

Moreover, the statistical nucleation rate of all five coatings was studied. According to our previous analysis, the statistical nucleation rate $R\left(T_{i}\right)$ at $T_{i}$ was binned with a width of $\Delta T_{i}=0.2^{\circ} \mathrm{C}$ which contains $n_{i}$ freezing events; then, 

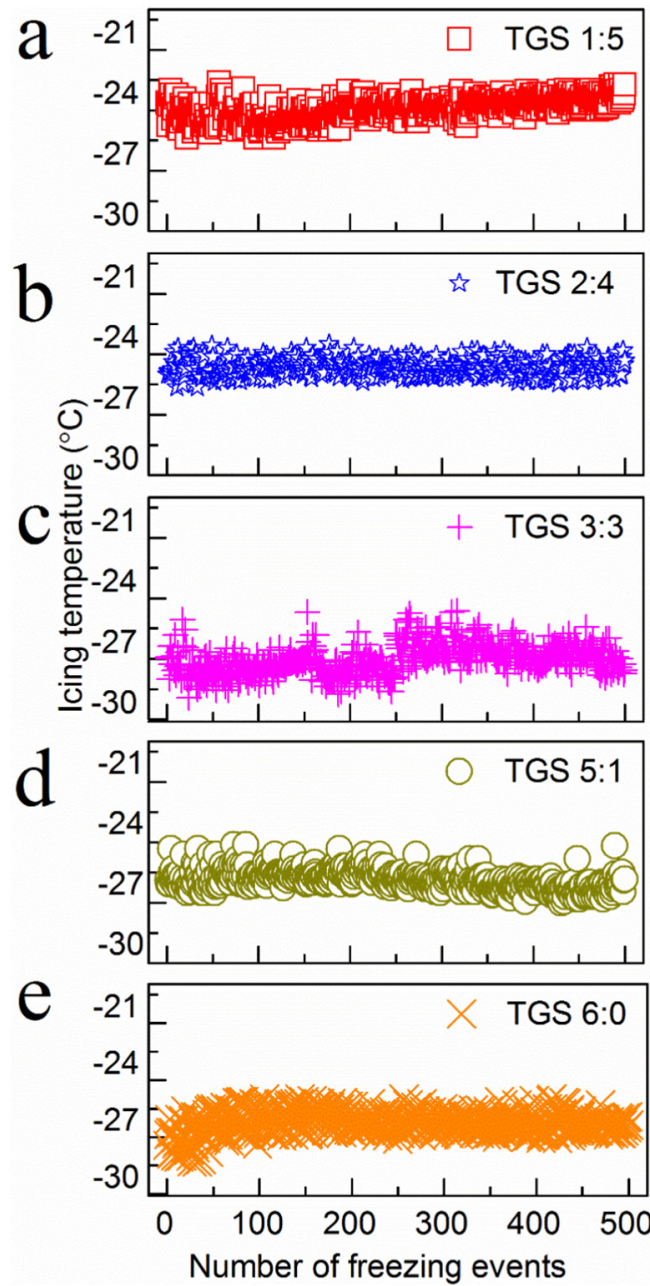

Fig. 4. Icing temperatures of (a) TGS 1:5, (b) TGS 2:4, (c) TGS 3:3, (d) TGS 5:1 and (e) TGS 6:0 coatings.

$R\left(T_{i}\right)=\frac{c n_{i}}{\Delta T_{i}\left(\frac{n_{i}}{2}+\sum_{j>i} n_{j}\right)}$,

where $c$ is the cooling rate $\left(5^{\circ} \mathrm{C} / \mathrm{min}\right.$ in the current experiment), $\sum_{\mathrm{j}>i} \mathrm{n}_{\mathrm{j}}$ is the sum of unfrozen icing events. Since ice-nucleation sites at the three-phase contact line on rough surfaces was observed directly in our previous studies [41,55], the corresponding line-nucleation rate can be expressed as

$R_{S}^{*}\left(T_{i}\right)=\frac{R\left(T_{i}\right)}{S}$,

where $S$ is the length of a three-phase contact line between a $10 \mu$ water droplet and a coating surface, calculated as $S=2 \pi r$, and the radius $r$ is given by [56]

$r=\left[\frac{3 V}{\pi\left(2-3 \cos \theta+\cos ^{3} \theta\right)}\right]^{1 / 3} \sin \theta$,

where $V$ is the volume of the water droplet, $\theta$ is the static water contact angle. In this equation, the three-phase contact lines of air-trapping sites in the three phase contact line was neglected based on a previously report that this did not markedly change the calculated results [45]. The calculated values of $r$ and $S$ are listed in Table 3. Consequently, the calculated $R_{S}{ }^{*}\left(T_{i}\right)$ of these coatings are shown in Fig. 7. Apparently, at a given temperature (marked with a grey line), the lowest line-nucleation rate was obtained for the TGS 3:3 coating, followed by the TGS 6:0 and TGS 5:1 coatings. A line-nucleation rate higher by two orders of magnitude for the TGS 1:5 and TGS 2:4 coatings indicates a fast icing
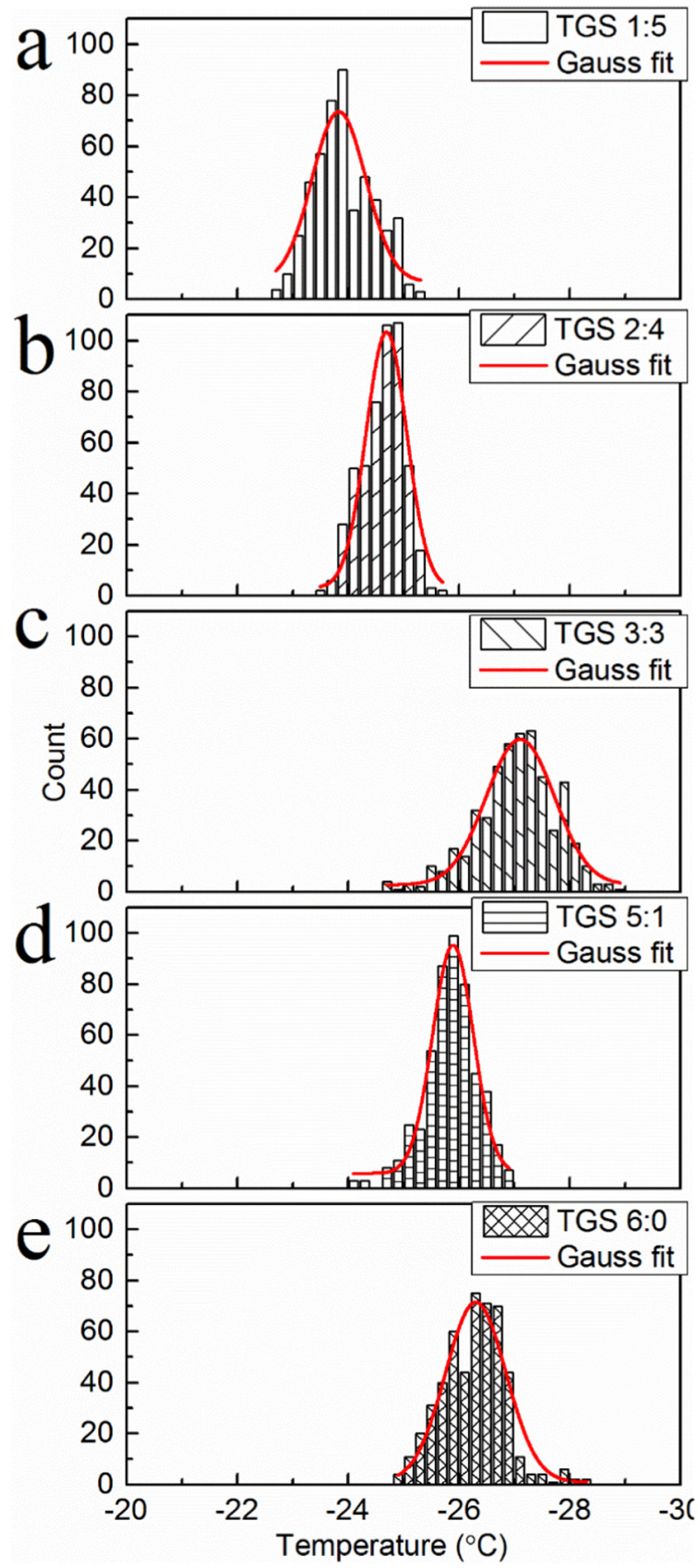

Fig. 5. Histogram of the icing events on (a) TGS 1:5, (b) TGS 2:4, (c) TGS 3:3, (d) TGS 5:1 and (e) TGS 6:0 coatings with a bin width of $0.2^{\circ} \mathrm{C}$.

Table 2

Statistic values of icing events on studied coatings.

\begin{tabular}{llll}
\hline Samples & Peak value $\left({ }^{\circ} \mathrm{C}\right)$ & $t_{0.5}\left({ }^{\circ} \mathrm{C}\right)$ & $10-90$ width $\left({ }^{\circ} \mathrm{C}\right)$ \\
\hline TGS 1:5 & -23.82 & -23.96 & 1.49 \\
TGS 2:4 & -24.70 & -24.77 & 0.69 \\
TGS 3:3 & -27.08 & -27.16 & 1.27 \\
TGS 5:1 & -25.90 & -25.96 & 2.17 \\
TGS 6:0 & -26.32 & -26.41 & 1.42 \\
\hline
\end{tabular}

process at a given temperature.

Ice nucleation happens randomly, not only at one site. Previous studies found that an ice-nucleation process was influenced by surface energy and surface microstructure. Lower surface energy and convex surfaces were favorable for lowering the icing temperatures [57-62]. 


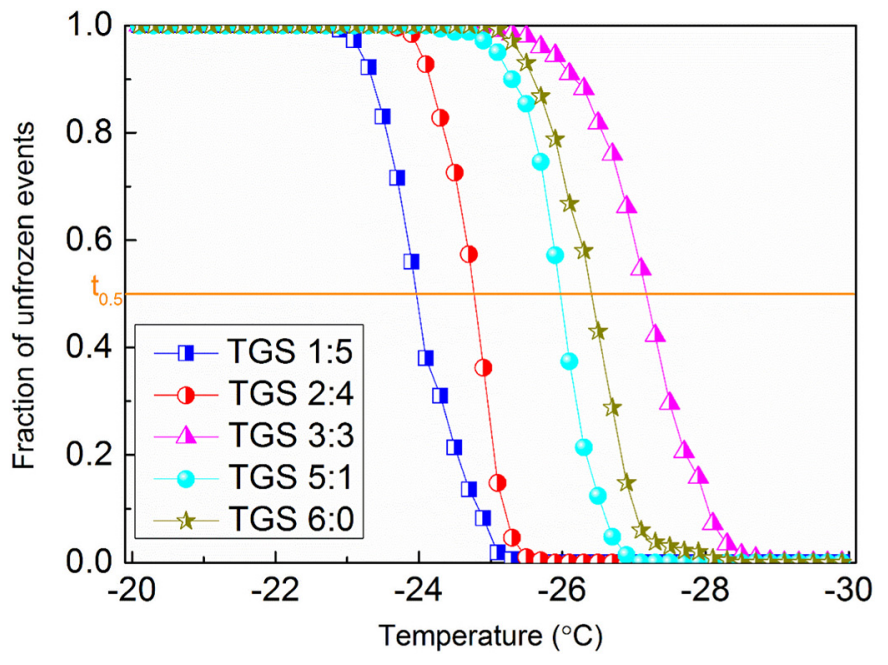

Fig. 6. Temperature-survival curves of studied coatings.

Table 3

Calculated radius and length of three-phase contact line for five coatings according to their water-contact angles.

\begin{tabular}{llllll}
\hline & TGS 1:5 & TGS 2:4 & TGS 3:3 & TGS 5:1 & TGS 6:0 \\
\hline$\theta\left({ }^{\circ}\right)$ & 160 & 168 & 162 & 165 & 169 \\
$r(\mathrm{~mm})$ & 0.46 & 0.28 & 0.41 & 0.35 & 0.26 \\
$S(\mathrm{~mm})$ & 2.87 & 1.75 & 2.59 & 2.17 & 1.60 \\
\hline
\end{tabular}

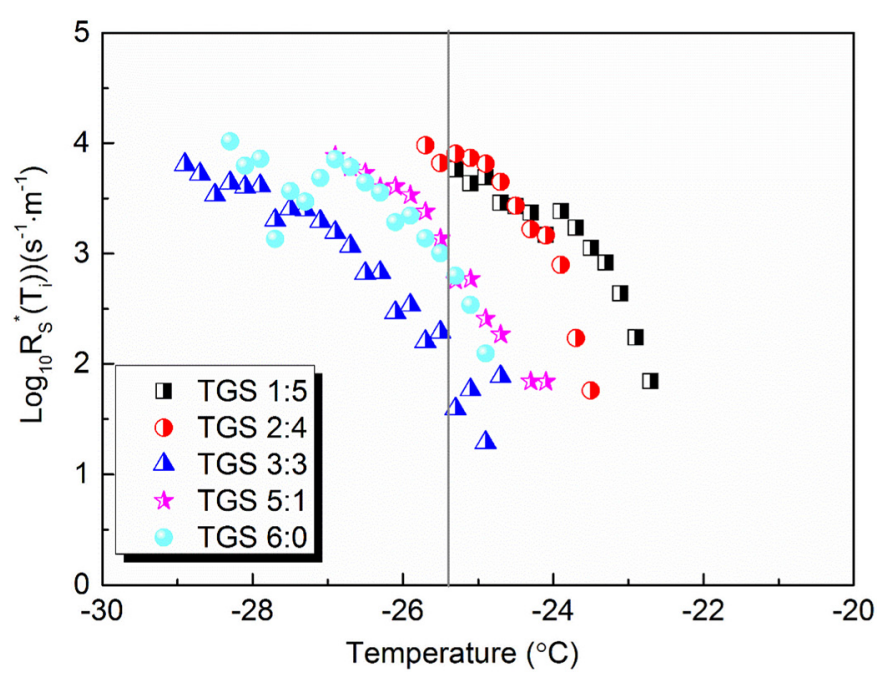

Fig. 7. Calculated line-nucleation rates of studied coatings.

Here, all five studied superhydrophobic coatings had a certain portion of convex structures and nearly no concave pores were observed on the TGS 1:5 coating. A very low line ice-nucleation rate was observed on the TGS 3:3 coating, corresponding to the lowest surface roughness and more uniform distribution of micro-pores. In addition, the TGS 6:0 coating, with a highest portion of PFOTES-SiO ${ }_{2}$ nanoparticles and the lowest ice adhesion, demonstrated a line ice-nucleation rate higher than that of the TGS 3:3 coating. These results imply that the level of surface roughness and the size of micro-pores affect the ice-nucleation process. Moreover, ice adhesion and ice nucleation share distinct underlying mechanisms. Ice adhesion to superhydrophobic coatings is mainly dominated by van der Waals forces and mechanical interlocking, while ice nucleation is related to the transformation of disordered water molecules to ordered ones, and the transformation is affected by the icewater interfacial tension [63], and surface features like pores, steps, cracks, etc. with sizes of the order of the critical nucleus [64]. The icenucleation process might be triggered at any suitable sites with a low free energy barrier. The unique surface feature of the TGS 3:3 coating is defined by its more uniform size and distribution of agglomerated nanoparticles than those of the other four coatings. This have contributed to the higher energy barrier of heterogeneous nucleation than for the other coating surfaces. This could explain its observed lowest icing temperature, icing probability and ice-nucleation rate.

An important revelation by the current work is that there is no simple correlation between the surface roughness and the icephobicity performance such as the ice-nucleation temperature and ice-adhesion strength. This is because a roughness reading does not provide lateral information and cannot differentiate surfaces with different microscopic features between peaks and valleys - surfaces with protruding peaks, cavity, and other irregularities may give the same roughness reading [65]. However, these detailed structures are critical in determining the ice nucleation and ice adhesion behavior. Therefore, detailed topology/geometry has to be considered when designing icephobic coatings, as discussed above.

\section{Conclusions}

Five superhydrophobic coatings with different surface structures were designed to investigate their anti-icing performance. The surface microscopic features were prepared by varying the ratio of nanoparticles with low and high surface energies while keeping their total amount constant. The ice-adhesion strength and icing temperature of the developed coatings were measured and analyzed. The effect of water condensation on ice adhesion of the five coatings verified the robust icephobicity of the TGS 6:0 coating against moisture condensation. It was found that the detailed surface geometry and surface energy of superhydrophobic coatings played important roles in the ice adhesion. The coatings with the ice-nucleation temperature and icing probability ranked from the lowest to the highest were TGS 3:3 < TGS 6:0 < TGS 5:1 < TGS 2:4 < TGS 1:5. The TGS 6:0 coating did not display the most retarded ice nucleation, but it presented an ice-nucleation temperature $\left(-26.4^{\circ} \mathrm{C}\right)$ close to the lowest TGS3:3 coating $\left(-27.16^{\circ} \mathrm{C}\right)$. From the materials-science point of view, it was revealed that reducing the ice adhesion and ice-nucleation temperature/rate have different requirements on surface geometry due to their different underlying mechanisms. Therefore, this study supports the view that superhydrophobicity does not automatically leads to icephobicity. Our work has pointed out that the strategy of preparing superhydrophobic coatings for icephobic applications can be realized when the surface topology is carefully designed.

\section{Acknowledgements}

Financial support from A*STAR Science and Engineering Research Council (Grant 1528000048) of the Singapore Government is gratefully acknowledged.

\section{References}

[1] Y. Shen, J. Tao, H. Tao, S. Chen, L. Pan, T. Wang, Anti-icing potential of superhydrophobic Ti6Al4V surfaces: ice nucleation and growth, Langmuir 31 (2015) 10799-10806.

[2] Q. Fu, D.K. Kumar, X. Wu, W.C. Ho, P.D. Kanhere, N. Srikanth, E. Liu, P. Wilson, Z. Chen, Development of sol-gel icephobic coatings: effect of surface roughness and surface energy, ACS Appl. Mater. Interfaces 6 (2014) 20685-20692.

[3] X. Wu, Q. Fu, D. Kumar, J.W.C. Ho, P. Kanhere, H. Zhou, Z. Chen, Mechanically robust superhydrophobic and superoleophobic coatings derived by sol-gel method, Mater. Des. 89 (2016) 1302-1309.

[4] D. Kumar, X. Wu, Q. Fu, J.W.C. Ho, P.D. Kanhere, L. Li, Z. Chen, Hydrophobic sol-gel coatings based on polydimethylsiloxane for self-cleaning applications, Mater. Des. 86 (2015) 855-862.

[5] Y.Z. Shen, H.J. Tao, S.L. Chen, L.M. Zhu, T. Wang, J. Tao, Icephobic/anti-icing potential of superhydrophobic Ti6Al4V surfaces with hierarchical textures, RSC Adv. 5 (2015) 1666-1672. 
[6] N. Saleema, M. Farzaneh, R.W. Paynter, D.K. Sarkar, Prevention of ice accretion on aluminum surfaces by enhancing their hydrophobic properties, J. Adhes. Sci. Technol. 25 (2011) 27-40.

[7] L. Boinovich, A.M. Emelyanenko, Role of water vapor desublimation in the adhesion of an iced droplet to a superhydrophobic surface, Langmuir 30 (2014) 12596-12601.

[8] K.Q. Zhang, J.Z. Cai, X.H. Li, H. Li, Y.H. Zhao, X.Y. Yuan, Balance of polyacrylatefluorosilicone block copolymers as icephobic coatings, Chin. J. Polym. Sci. 33 (2015) 153-162.

[9] H. Li, Y.H. Zhao, X.Y. Yuan, Facile preparation of superhydrophobic coating by spraying a fluorinated acrylic random copolymer micelle solution, Soft Matter 9 (2013) 1005-1009.

[10] X.H. Wu, X. Zhao, J.W.C. Ho, Z. Chen, Design and durability study of environmental-friendly room-temperature processable icephobic coatings, Chem. Eng. J. 355 (2019) 901-909.

[11] X.L. Zhan, Y.D. Yan, Q.H. Zhang, F.Q. Chen, A novel superhydrophobic hybrid nanocomposite material prepared by surface-initiated AGET ATRP and its anti-icing properties, J. Mater. Chem. A 2 (2014) 9390-9399.

[12] F.T. Liu, F.H. Sun, Q.M. Pan, Highly compressible and stretchable superhydrophobic coating inspired by bio-adhesion of marine mussels, J. Mater. Chem. A 2 (2014) 11365-11371.

[13] S.H. Park, E.H. Cho, J. Sohn, P. Theilmann, K. Chu, S. Lee, Y. Sohn, D. Kim, B. Kim, Design of multi-functional dual hole patterned carbon nanotube composites with superhydrophobicity and durability, Nano Res. 6 (2013) 389-398.

[14] D.P. Singh, J.P. Singh, Controlled growth of standing Ag nanorod arrays on bare Si substrate using glancing angle deposition for self-cleaning applications, Appl. Phys. A Mater. 114 (2014) 1189-1193.

[15] R. Asmatulu, M. Ceylan, N. Nuraje, Study of superhydrophobic electrospun nanocomposite fibers for energy systems, Langmuir 27 (2011) 504-507.

[16] T. Maitra, S. Jung, M.E. Giger, V. Kandrical, T. Ruesch, D. Poulikakos, Superhydrophobicity vs. ice adhesion: the quandary of robust icephobic surface design, Adv. Mater. Interfaces 2 (2015) 1500330.

[17] H. Saito, K. Takai, G. Yamauchi, Water-and ice-repellent coatings, Surf. Coat. Int. B: Coat. Trans. 80 (1997) 168-171.

[18] L.L. Cao, A.K. Jones, V.K. Sikka, J.Z. Wu, D. Gao, Anti-icing superhydrophobic coatings, Langmuir 25 (2009) 12444-12448.

[19] G. Momen, M. Farzaneh, Simple process to fabricate a superhydrophobic coating, Micro Nano Lett. 6 (2011) 405-407.

[20] R. Jafari, R. Menini, M. Farzaneh, Superhydrophobic and icephobic surfaces prepared by RF-sputtered polytetrafluoroethylene coatings, Appl. Surf. Sci. 257 (2010) 1540-1543.

[21] Y. Zhao, J. Li, J. Hu, S. Grzybowski, Icing performances of super-hydrophobic PDMS/Nano-silica hybrid coating on insulators, High Voltage Engineering and Application (ICHVE), 2010 International Conference on, 2010, pp. 489-492.

[22] M. He, J.X. Wang, H.L. Li, X.L. Jin, J.J. Wang, B.Q. Liu, Y.L. Song, Super-hydrophobic film retards frost formation, Soft Matter 6 (2010) 2396.

[23] L. Mishchenko, B. Hatton, V. Bahadur, J.A. Taylor, T. Krupenkin, J. Aizenberg, Design of ice-free nanostructured surfaces based on repulsion of impacting water droplets, ACS Nano 4 (2010) 7699-7707.

[24] T. Furuta, M. Sakai, T. Isobe, A. Nakajima, Effect of dew condensation on the wettability of rough hydrophobic surfaces coated with two different silanes, Langmuir 26 (2010) 13305-13309.

[25] R. Karmouch, G.G. Ross, Experimental study on the evolution of contact angles with temperature near the freezing point, J. Phys. Chem. C 114 (2010) 4063-4066.

[26] L. Yin, Q. Xia, J.A. Xue, S.Q. Yang, Q.J. Wang, Q.M. Chen, In situ investigation of ice formation on surfaces with representative wettability, Appl. Surf. Sci. 256 (2010) 6764-6769.

[27] K.K. Varanasi, T. Deng, J.D. Smith, M. Hsu, N. Bhate, Frost formation and ice adhesion on superhydrophobic surfaces, Appl. Phys. Lett. 97 (2010) 234102.

[28] M. He, H.L. Li, J.J. Wang, Y.L. Song, Superhydrophobic surface at low surface temperature, Appl. Phys. Lett. 98 (2011) 093118.

[29] M. He, J.J. Wang, H.L. Li, Y.L. Song, Super-hydrophobic surfaces to condensed micro-droplets at temperatures below the freezing point retard ice/frost formation, Soft Matter 7 (2011) 3993-4000.

[30] F. Wang, C. Li, Y. Lv, F. Lv, Y. Du, Ice accretion on superhydrophobic aluminum surfaces under low-temperature conditions, Cold Reg. Sci. Technol. 62 (2010) 2933.

[31] C. Antonini, M. Innocenti, T. Horn, M. Marengo, A. Amirfazli, Understanding the effect of superhydrophobic coatings on energy reduction in anti-icing systems, Cold Reg. Sci. Technol. 67 (2011) 58-67.

[32] Y. Tang, Q. Zhang, X. Zhan, F. Chen, Superhydrophobic and anti-icing properties at overcooled temperature of a fluorinated hybrid surface prepared via a sol-gel process, Soft Matter 11 (2015) 4540-4550.

[33] L. Wang, Q. Gong, S. Zhan, L. Jiang, Y. Zheng, Robust anti-icing performance of a flexible superhydrophobic surface, Adv. Mater. 28 (2016) 7729-7735.

[34] Y. Shen, G. Wang, J. Tao, C. Zhu, S. Liu, M. Jin, Y. Xie, Z. Chen, Anti-icing performance of superhydrophobic texture surfaces depending on reference environments, Adv. Mater. Interfaces 4 (2017) 1700836.

[35] A.M. Emelyanenko, L.B. Boinovich, A.A. Bezdomnikov, E.V. Chulkova, K.A. Emelyanenko, Reinforced superhydrophobic coating on silicone rubber for longstanding anti-icing performance in severe conditions, ACS Appl. Mater. Interfaces 9 (2017) 24210-24219.

[36] J.C. Moreno-Pirajan, Thermodynamics-interaction studies-solids, liquids and gases, Thermodynamics Approach in the Adsorption of Heavy Metals, In Tech, Croatia, Europe, 2011, , https://doi.org/10.5772/21326.

[37] D. Bassett, E. Boucher, A. Zettlemoyer, Adsorption studies on ice-nucleating substrates. Hydrophobed silicas and silver iodide, J. Colloid Interface Sci. 34 (1970) 436-446.

[38] P. Judeinstein, C. Sanchez, Hybrid organic-inorganic materials: a land of multidisciplinarity, J. Mater. Chem. 6 (1996) 511-525.

[39] X. Wu, S. Zheng, D.A. Bellido-Aguilar, V.V. Silberschmidt, Z. Chen, Transparent icephobic coatings using bio-based epoxy resin, Mater. Des. 140 (2018) 516-523.

[40] K.Y. Li, S. Xu, W.X. Shi, M. He, H.L. Li, S.Z. Li, X. Zhou, J.J. Wang, Y.L. Song, Investigating the effects of solid surfaces on ice nucleation, Langmuir 28 (2012) 10749-10754.

[41] X. Wu, Z. Chen, A mechanically robust transparent coating for anti-icing and selfcleaning applications, J. Mater. Chem. A 6 (2018) 16043-16057.

[42] D.K. Owens, R. Wendt, Estimation of the surface free energy of polymers, J. Appl. Polym. Sci. 13 (1969) 1741-1747.

[43] W. Rabel, Wetting theory and its application to the study and use of the surface properties of polymers, Farbe und Lack, 77 1971, pp. 997-1006.

[44] D. Kaelble, Dispersion-polar surface tension properties of organic solids, J. Adhes. 2 (1970) 66-81.

[45] Q.T. Fu, E.J. Liu, P. Wilson, Z. Chen, Ice nucleation behaviour on sol-gel coatings with different surface energy and roughness, Phys. Chem. Chem. Phys. 17 (2015) 21492-21500.

[46] V. Hejazi, K. Sobolev, M. Nosonovsky, From superhydrophobicity to icephobicity: forces and interaction analysis, Sci. Rep. 3 (2013) 2194.

[47] K. Golovin, S.P. Kobaku, D.H. Lee, E.T. DiLoreto, J.M. Mabry, A. Tuteja, Designing durable icephobic surfaces, Sci. Adv. 2 (2016) e1501496.

[48] T.F. Whale, B.J. Murray, D. O'Sullivan, T.W. Wilson, N.S. Umo, K.J. Baustian, J.D. Atkinson, D.A. Workneh, G.J. Morris, A technique for quantifying heterogeneous ice nucleation in microlitre supercooled water droplets, Atmos. Meas. Tech. 8 (2015) 2437-2447.

[49] P. Wilson, A. Haymet, Effect of solutes on the heterogeneous nucleation temperature of supercooled water: an experimental determination, Phys. Chem. Chem. Phys. 11 (2009) 2679-2682.

[50] P.W. Wilson, K.E. Osterday, A.F. Heneghan, A.D. Haymet, Type I antifreeze proteins enhance ice nucleation above certain concentrations, J. Biol. Chem. 285 (2010) 34741-34745.

[51] T. Verho, C. Bower, P. Andrew, S. Franssila, O. Ikkala, R.H.A. Ras, Mechanically durable superhydrophobic surfaces, Adv. Mater. 23 (2011) 673-678.

[52] P.W. Wilson, W. Lu, H. Xu, P. Kim, M.J. Kreder, J. Alvarenga, J. Aizenberg, Inhibition of ice nucleation by slippery liquid-infused porous surfaces (SLIPS), Phys. Chem. Chem. Phys. 15 (2013) 581-585.

[53] P.W. Wilson, A.F. Heneghan, A.D.J. Haymet, Ice nucleation in nature: supercooling point (SCP) measurements and the role of heterogeneous nucleation, Cryobiology 46 (2003) 88-98.

[54] P.W. Wilson, A.D.J. Haymet, The spread of nucleation temperatures of a sample of supercooled liquid is independent of the average nucleation temperature, J. Phys. Chem. B 116 (2012) 13472-13475.

[55] X. Wu, Y. Tang, V.V. Silberschmidt, P. Wilson, Z. Chen, Mechanically robust transparent anti-Icing coatings: roles of dispersion status of titanate nanotubes, Adv. Mater. Interfaces 5 (2018) 18007735.

[56] P. Hao, C. Lv, X. Zhang, Freezing of sessile water droplets on surfaces with various roughness and wettability, Appl. Phys. Lett. 104 (2014) 161609.

[57] M.J. Jamieson, C.E. Nicholson, S.J. Cooper, First study on the effects of interfacial curvature and additive interfacial density on heterogeneous nucleation. Ice crystallization in oil-in-water emulsions and nanoemulsions with added 1-heptacosanol, Cryst. Growth Des. 5 (2005) 451-459.

[58] D.H. Xu, W.L. Johnson, Geometric model for the critical-value problem of nucleation phenomena containing the size effect of nucleating agent, Phys. Rev. B 72 (2005) 052101.

[59] S.J. Cooper, C.E. Nicholson, J. Liu, A simple classical model for predicting onset crystallization temperatures on curved substrates and its implications for phase transitions in confined volumes, J. Chem. Phys. 129 (2008) 124715.

[60] N.H. Fletcher, Size effect in hetergeneous nucleation, J. Chem. Phys. 29 (1958) 572-576.

[61] B.K. Chakraverty, G.M. Pound, Hetergeneous nucleation at macroscopic steps, Acta Metall. 12 (1964) 851-860.

[62] C.A. Sholl, N.H. Fletcher, Decoration criteria for surface steps, Acta Metall. 18 (1970) 1083-1086.

[63] L. Ickes, A. Welti, C. Hoose, U. Lohmann, Classical nucleation theory of homogeneous freezing of water: thermodynamic and kinetic parameters, Phys. Chem. Chem. Phys. 17 (2015) 5514-5537.

[64] C. Gurganus, J. Charnawskas, A. Kostinski, R. Shaw, Nucleation at the contact line observed on nanotextured surfaces, Phys. Rev. Lett. 113 (2014) 235701.

[65] B. Zheng, L.P. Wong, L.Y.L. Wu, Z. Chen, Identifying key factors towards highly reflective silver coatings, Adv. Mater. Sci. Eng. (2017) 7686983(1-12). 